Article

\title{
Application of a High-Density Temperature Measurement System for the Management of the Kaohsiung House Project
}

\author{
Chien-Chiao Chao ${ }^{1,2}$, Kuo-An Hung ${ }^{3, *(1)}$, Szu-Yuan Chen ${ }^{3}\left(\mathbb{D}\right.$, Feng-Yi $\operatorname{Lin}^{4}\left(\mathbb{D}\right.$ and Tzu-Ping Lin ${ }^{3} \mathbb{(}$ \\ 1 College of Engineering, National Kaohsiung University of Science and Technology, Kaohsiung 82445, Taiwan; \\ aajoe@kcg.gov.tw \\ 2 Kaohsiung City Government, Kaohsiung 80027, Taiwan \\ 3 Department of Architecture, National Cheng Kung University, Tainan 70101, Taiwan; \\ bettypigy@gmail.com (S.-Y.C.); lin678@gmail.com (T.-P.L.) \\ 4 Green Energy and Environment Research Laboratories, Industrial Technology Research Institute, \\ Hsinchu 31057, Taiwan; itriA90070@itri.org.tw \\ * Correspondence: hungkuoan@gmail.com
}

Citation: Chao, C.-C.; Hung, K.-A.; Chen, S.-Y.; Lin, F.-Y.; Lin, T.-P. Application of a High-Density Temperature Measurement System for the Management of the Kaohsiung House Project. Sustainability 2021, 13, 960. https://doi.org/10.3390/ su13020960

Received: 30 December 2020

Accepted: 14 January 2021

Published: 19 January 202

Publisher's Note: MDPI stays neutral with regard to jurisdictional claims in published maps and institutional affiliations.

Copyright: (c) 2021 by the authors. Licensee MDPI, Basel, Switzerland. This article is an open access article distributed under the terms and conditions of the Creative Commons Attribution (CC BY) license (https:// creativecommons.org/licenses/by/ $4.0 /)$.

\begin{abstract}
In Taiwan, the daytime temperature usually exceeds $37^{\circ} \mathrm{C}$ in summer, and the increase in air-conditioning usage has led to higher energy demand, which brings a heavy burden to power plants. The Kaohsiung House Project, undertaken by the city government, encourages the installation of greening facilities in buildings, such as photovoltaic (PV) panels on rooftops and vertical gardens on balconies, in order to preserve energy and reduce carbon emissions. In the present study, the urban heat island effect and temperature distribution within the city was examined through the establishment of 16 temperature measurement sites within a $7.5 \mathrm{~km} \times 6 \mathrm{~km}$ area. A betweensite temperature difference of $2{ }^{\circ} \mathrm{C}$ was observed between April and August. Areas with higher temperature are recommended to increase their green space ratio through the project. Moreover, relocating PV panels in low-temperature areas increased the overall generation efficiency by $0.8 \%$. Through the analysis of the measured data, this study determined which areas were more appropriate for green space expansion, and which would best serve for green energy generation, all with the aim of improving external environmental comfort and maximizing carbon reduction. Recommendations regarding the implementation of subsequent policies were issued and they provide reference for implementation in other cities.
\end{abstract}

Keywords: urban heat island; solar energy; temperature measurement; urban greenery

\section{Introduction}

The Taiwan Green House Reduction and Management Act, which was passed in 2015, stipulates that, by 2050, national greenhouse gas emissions will have decreased to $50 \%$ of those in 2005. In recent years, the Taiwanese government has actively incorporated the use of green energy in urban development plans. With the rapid progression of urbanization, urban heat island effect has been observed in multiple cities. Large population, high building density, and busy traffic in these cities inevitably lead to the excessive accumulation and poor dissipation of heat, directly affecting the quality of life. Moreover, the urban heat island effect increases air conditioning usage in summer, which leads to continual increases in urban energy demand and consumption [1]. Various research has proposed, mitigating the urban heat island effect by different approaches [2,3] and reducing energy consumption through the retention or creation of sufficient green space and areas of vegetation [4-9]. Green roofs are also effective for reducing the ambient temperature $[10,11]$. Community policies that are related to green energy have not only been actively promoted in Taiwan; in Japan, for example, the Fujisawa Sustainable Smart Town has installed photovoltaic (PV) panels in all houses to supply energy for local residents [12]. 


\subsection{Greening and Energy Policies of the Kaohsiung House Project}

Kaohsiung City is one of the oldest zones of major development in Taiwan. According to the data made by the Ministry of the Interior in Taiwan (2018), the city ranks third in population among the six special municipalities of Taiwan. The population density in the city center is extremely high. This can be partially attributed to the ecological restoration of Love River, and the expansion of the mass rapid transit system, which, in recent years, has enabled the government to accelerate the development of areas in the periphery of downtown.

The implementation of the Kaohsiung House Project, a green building initiative that was undertaken by the city government, began in 2012. The principal foci are environmental sustainability, the showcasing of local characteristics, and resident health [13]. Through the implementation of construction and design standards, evaluation indexes, and relevant certification systems, the city government encourages the architects involved to incorporate local materials into the building design and take unique place characteristics into account [14]. The project promotes the use of permeable foundations, deep verandas, green roofs, and PV panels to ensure environmental sustainability and reductions in residential temperature [15-18].

\subsection{Calculation of Energy Generation from PV Panels and Its Relationship with Temperature}

Studies have established that the environment exerts substantial effects on the potential for green energy generation. For example, Santiago et al. examined the effect of environments on generation efficiency by installing a temperature sensor on a $(164.5 \mathrm{~cm} \times 99 \mathrm{~cm})$ $\mathrm{PV}$ panel and measuring the temperature on its front and back surfaces. The panel was also connected to an inverter in order to measure the actual energy output [19]. Previous studies input the point cloud data of buildings into VOSTOK software to simulate the reception and shading of solar radiation at each data point and the effect of solar radiation on their generation efficiency $[20,21]$. Corea-Betanzo et al. explored the effect of ambient temperature and wind speed on the generation efficiency of PV panels, reporting that the efficiency improved by more than $10 \%$ when the wind speed reached $15 \mathrm{~m} / \mathrm{s}$ [22]. Relative ambient humidity and dust concentration also affect the generation efficiency of PV panels. Specifically, dust particles reduce the exposure of PV panels to solar radiation, whereas high humidity results in the formation of dew, which traps dust particles on the panel surface [23].

Dubey et al. asserted that operating temperature is the main factor affecting the generation efficiency of the PV modules [24]. By contrast, another study identified solar radiation and panel temperature as the main factors [25]. Pinho and Galdino explored the effect of radiation level and panel temperature on generation efficiency [26]. The module generated $20 \mathrm{~V}$ of power when the solar radiation level was $200 \mathrm{~W} / \mathrm{m}^{2}$ at the standard temperature of $25^{\circ} \mathrm{C}$. When the panel temperature and solar radiation level were increased to $75^{\circ} \mathrm{C}$ and $1000 \mathrm{~W} / \mathrm{m}^{2}$, respectively, the module generated $17.5 \mathrm{~V}$ of power, which was $4.5 \mathrm{~V}$ less than that when the temperature was $25^{\circ} \mathrm{C}$. This confirmed that increasing the panel temperature reduces the amount of voltage generated.

Pan et al. used ambient temperature as the main variable for assessing the generation efficiency of PV panels in the southern suburbs of Beijing. Specifically, they measured the temperatures of the air, ground surface, and the panels themselves, and used regression analysis in order to determine the correlation between ambient temperature and panel temperature. They discovered that the PV panel temperatures derived from the ambient temperature data was approximately that of the actual panel temperature (correlation coefficient 0.88 ). This demonstrates that ambient temperature can be used to directly estimate the temperature of a PV panel, calculate the temperature reduction coefficient, and determine the generation efficiency [27]. The literature discussed thus far indicates that high ambient temperature increases the temperature of PV modules, which, in turn, detrimentally affects the generation efficiency. Therefore, the present study focuses on 
determining the temperature distribution in Kaohsiung and using the temperature data in order to estimate the generation efficiency of PV panels in the city.

Temperature distributions can be established while using various methods. Honjo et al. set up 200 sites for the measurement of temperature and relative humidity in urban and suburban areas in the coastal and inland regions of Tokyo [28]. In their assessment of the urban heat island effect in Taiwan, Lin et al. collected data by installing a temperature recorder on a car and traveling along specific routes in Tainan, Kaohsiung, and Hsinchu on sunny days [2]. Chen et al. divided Tainan into a grid of squares measuring $2.75 \mathrm{~km} \times 2.75 \mathrm{~km}$ and installed monitors for temperature measurement across 100 sites in areas of mixed land use [29].

Multiple factors affect the generation efficiency of PV panels. In the present study, a temperature monitoring network was constructed in order to explore the effect of temperature on PV panels' generation efficiency.

\subsection{Measurement of Urban Temperature Distribution}

Temperature data were visualized while using graphs of distributions of urban temperature, panel temperature, and temperature reduction coefficients. An interpolation method was formulated and ambient temperature was calculated with reference from the data and research methods that were used in relevant studies. Eldrandaly and Abu-Zaid explored the accuracy of and differences between various interpolation methods in a geographical information system (GIS), while using root mean square errors (RMSEs) to determine the errors in the values derived through these methods, in order to address the autocorrelation problem in temperature data collected from different measurement sites [30]. Among the six interpolation methods, namely: inverse distance weighting; global polynomial interpolation; local polynomial interpolation; radial basis function kernel; Ordinary Kriging; and, Universal Kriging, Ordinary Kriging and Universal Kriging yielded the most accurate results. In their analysis of groundwater in Gilan Province in northern Iran, Seyedmohammadi et al. established 341 sampling sites. They used RMSEs to compare five interpolation methods, namely: inverse distance weighting; global polynomial interpolation; local polynomial interpolation; radial basis function kernel; and, Ordinary Kriging. Ordinary Kriging yielded the smallest margin of error [31]. These results suggest that Kriging is the optimal interpolation method for analyzing data that were collected from multiple measurement sites.

The present objective was to collect temperature data and build a temperature distribution graph of Kaohsiung. Taking the specifications of panel installation and roof and balcony greening measures under the Kaohsiung House Project into account, the temperatures in each administrative district of the city were compared. Recommendations for the implementation of these measures in areas of high and low temperatures were provided.

\section{Methods}

\subsection{Establishment of the Measurement Sites}

This study made suggestions for the promotion of future policies through the evaluation of the current implementation status of the Kaohsiung House Project. Figure 1 presents the research framework. Notably, the Kaohsiung House Project was the first project in Taiwan to promote the construction of green buildings with local urban characteristics. Statistics on the green space built and the PV panels installed under the project have yet to be compiled. Therefore, in the present study, these calculations were made while using data from construction projects approved by the city government over the course of the Kaohsiung House Project. A dense temperature monitoring network was established. Interpolation was performed with the collected temperature data in order to graphically present the city's temperature distribution while using a GIS and, thereby, identify regions with high and low temperatures. Data regarding the areas of major green spaces in Kaohsiung were sourced from the city government. These data, along with that of the green spaces created and panels installed, were compared and overlaid with the temperature 
distribution graphs of high- and low-temperature zones to determine the areas in each administrative district that demonstrate potential for the construction of green space or green energy facilities as part of the project. The present results were shared with the city government as a reference for the promotion of subsequent measures.

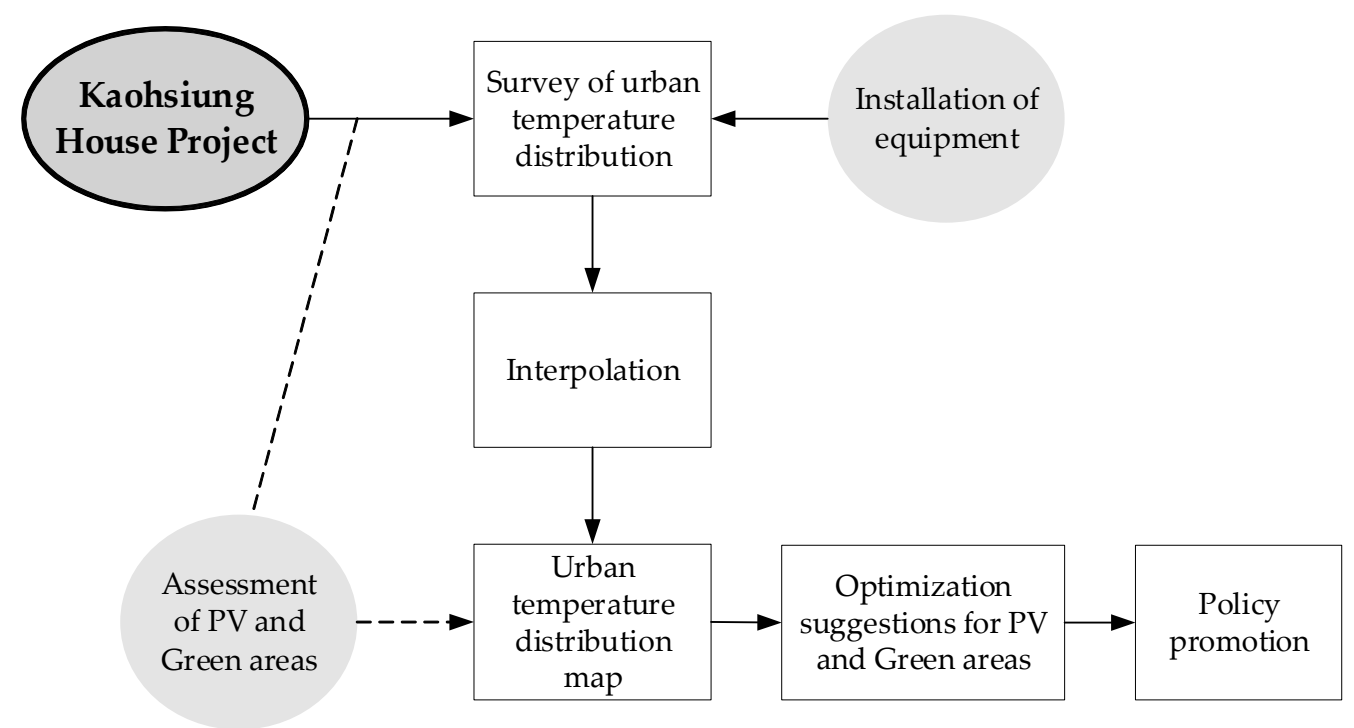

Figure 1. Research framework.

The temperature monitoring network encompassed the areas of Kaohsiung targeted for urban development. The total network area spanned $7.5 \mathrm{~km} \times 6 \mathrm{~km}$ and covered multiple landscapes, including mountainous periphery, high-population residential areas, and river canals. In order to effectively measure the temperature in different regions, the method that was employed by Chen et al. was adopted [32]. Specifically, the network was divided into a grid with squares of $2.75 \mathrm{~km} \times 2.75 \mathrm{~km}$. Subsequently, 16 measurement sites were selected from the grid. Sites D11 and D13 were located near Shoushan National Nature Park (elevation 356 m), as shown in Figure 2. Sites E12 and E14 were on the left bank of Love River. Sites F13 and H13 were located in Kaohsiung Main Station and along the main traffic route, respectively. Figure 3 presents the measurement equipment installed at site E12, which was located in the Zhongdu Wetlands Park.
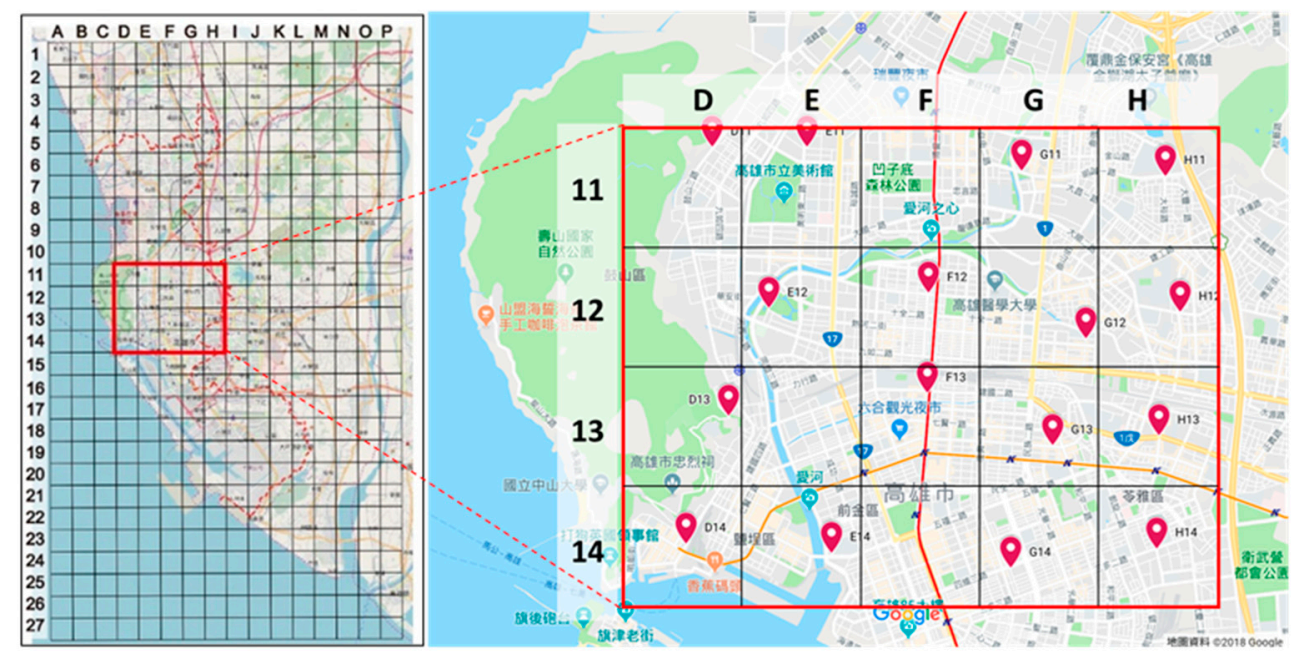

Figure 2. Distribution of measurement sites in the research area. 


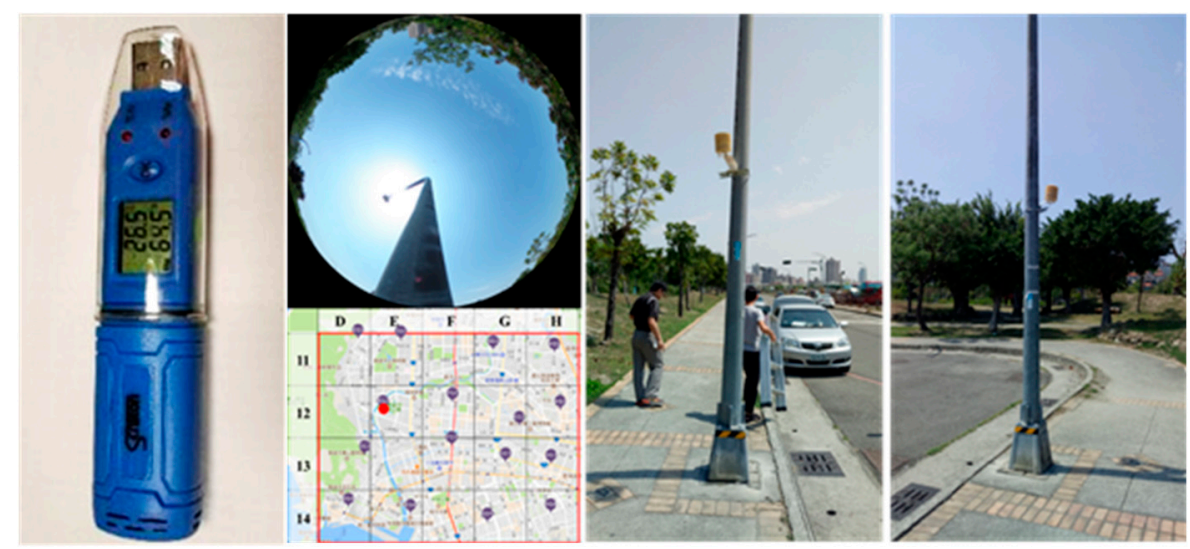

Figure 3. The measurement equipment (LOGPRO TR-32, Tecpel Co., Ltd.,New Taipei City, Taiwan) installed at site E12 in the Zhongdu Wetlands Park.

The temperature measurement devices were installed on streetlight poles at a height of $2.5 \mathrm{~m}$. In locations with no shade, they were calibrated before installation. The temperature and humidity data measurements were taken once every $150 \mathrm{~s}$ (precision $= \pm 0.5^{\circ} \mathrm{C}$ ) and 300 $\mathrm{s}$, respectively, with two readings that were collected at a time and the average of the two values being recorded as the measured value. The collected data were then downloaded to a computer while using a universal serial bus device and stored in Microsoft Excel file format.

Equipment setup at the 16 sites was performed between 24 March and 23 May 2018. Meteorological data were collected between 23 May 2018 and 7 January 2019, a total of 289 days.

\subsection{Interpolation}

Kriging was selected as the interpolation method in the present study for the aforementioned reasons. In spatial estimation, this method focuses on local analysis, accurately presenting the spatial characteristics of local variables. Kriging is further divided into Simple Kriging, Ordinary Kriging, and Universal Kriging. Ordinary Kriging is widely used in various fields, because it yields unbiased, linear, highly accurate estimates [32]. Equation (1) presents the Ordinary Kriging formula [33]:

$$
\hat{Z}\left(x_{0}\right)=\sum_{i=1}^{n} \lambda_{i} z\left(x_{i}\right)
$$

where:

$\hat{Z}\left(x_{0}\right)$ The estimated value at $x_{0}$

$z\left(x_{i}\right)$ The observed value at $x_{i}$

$n$ The sample sizes

$\lambda_{i}$ Kriging weight coefficient

Each weight coefficient was determined according to the distance between two sampling sites. The sum of all the coefficients equals 1, as expressed in Equation (2):

$$
\sum_{i=1}^{n} \lambda_{i}=1
$$

In this study, Kriging interpolation was performed in ArcGIS. Equations (1) and (2) were used in order to estimate the temperature at each site to create a temperature distribution graph. RMSEs were used to determine the optimal calculation formula in Geostatistical Wizard. Table 1 lists the configuration of the parameters that were used for interpolation. 
Table 1. Geographical information system (GIS) interpolation parameter settings.

\begin{tabular}{cc}
\hline Parameter & Setting \\
\hline Type of Kriging method & Ordinary Kriging \\
Output surface type & Prediction \\
Variance function/covariance & Covariance \\
Model type & Hole Effect \\
Type of neighbor & Smooth \\
Kriging weight & According to the location of each measurement site \\
\hline
\end{tabular}

\subsection{Calculation of the Power Generation Rate of PV Panels}

The in-depth review of related literature indicated that ambient temperature and solar radiation are crucial factors in assessing the generation efficiency of PV panels. These two factors can be used in order to calculate the temperature and thermal energy of a PV module. In simulations, ambient temperature and solar radiation per unit area can be used to derive the module temperature and assess the generation efficiency of PV modules, as presented in Equation (3) [34], which is commonly used to estimate the temperature of PV modules:

$$
T_{m}=T_{a m b}+(N O C T-20) \times E / 800
$$

where:

$T_{m}$ Module Temperature

$T_{a m b}$ Ambient Temperature

NOCT Nominal Operation Cell Temperature

$E$ Irradiance in $\mathrm{W} / \mathrm{m}^{2}$

Hu et al. performed measurements of direct normal irradiance, ambient temperature, and relative humidity on a sunny summer day in order to explore the simulation accuracy of a solar power system [35]. Solar radiation and ambient temperature exhibited similar hourly distribution trends, which indicated that they were related. Ambient temperature, as measured through Equation (4), was used to assess the generation efficiency of the PV panels in the present study. Previous research used this equation to measure ambient temperature over the course of one year and determine its relationship with PV panel temperature [27]:

$$
T_{\text {cell }}=1.07 \times T_{\text {air }}+6.12
$$

where:

$T_{\text {cell }}$ PV panel temperature

$T_{\text {air }}$ Air temperature

The temperature of a PV panel determines the extent of reduction in energy generation efficiency. The temperature reduction coefficient $C_{T}$ denotes the effect of operation temperature on generation efficiency. Therefore, Equation (5) was devised for demonstrating this effect [27]:

$$
C_{T}=\left(T_{\text {cell }}-T_{0}\right) \times r
$$

where:

$C_{T}$ Temperature reduction coefficient

$T_{\text {cell }}$ PV panel temperature

$T_{0}$ Standard Operating Temperature $\left(25^{\circ} \mathrm{C}\right)$

$r$ Temperature effect coefficient

The temperature effect coefficient $r$ varies depending on the specifications of PV modules that are produced by different manufacturers, as well as the materials and techniques that are used in the manufacturing process. In previous studies, this coefficient was determined to be $-0.4 \%$ [27]. The PV panel temperature $\left(T_{\text {cell }}\right)$ can be derived from Equation (4); next, Equation (5) can be used in order to determine the percentage of power generation 
loss. This indicates that, when the module temperature exceeds $25^{\circ} \mathrm{C}$, each increment of $1{ }^{\circ} \mathrm{C}$ reduces the generation efficiency by $0.4 \%$ [27].

\subsection{Calculation of the Area of the Existing Green Space in Kaohsiung}

The coverage area and sufficiency of the existing green space in Kaohsiung was first determined in order to examine the effects of greening on the alleviation of the urban heat island effect. Land use classification data was acquired from the National Land Surveying and Mapping Center. The data on land classified as parks, green spaces, and plazas were used as the background data representing the total area of green space in the city. These data were then used to extract GIS (Figure 4) in order to calculate the total area of green space in each administrative district. The area of green space and the total area of land in each administrative district comprised the numerator and denominator of the green space ratio, respectively. Notably, Gushan District encompassed Shoushan National Nature Park, where both the building and population density is low. Because the park, which constitutes a large area of green space, is generally not considered to be a part of the city, it was excluded from the calculation of the green space ratio.

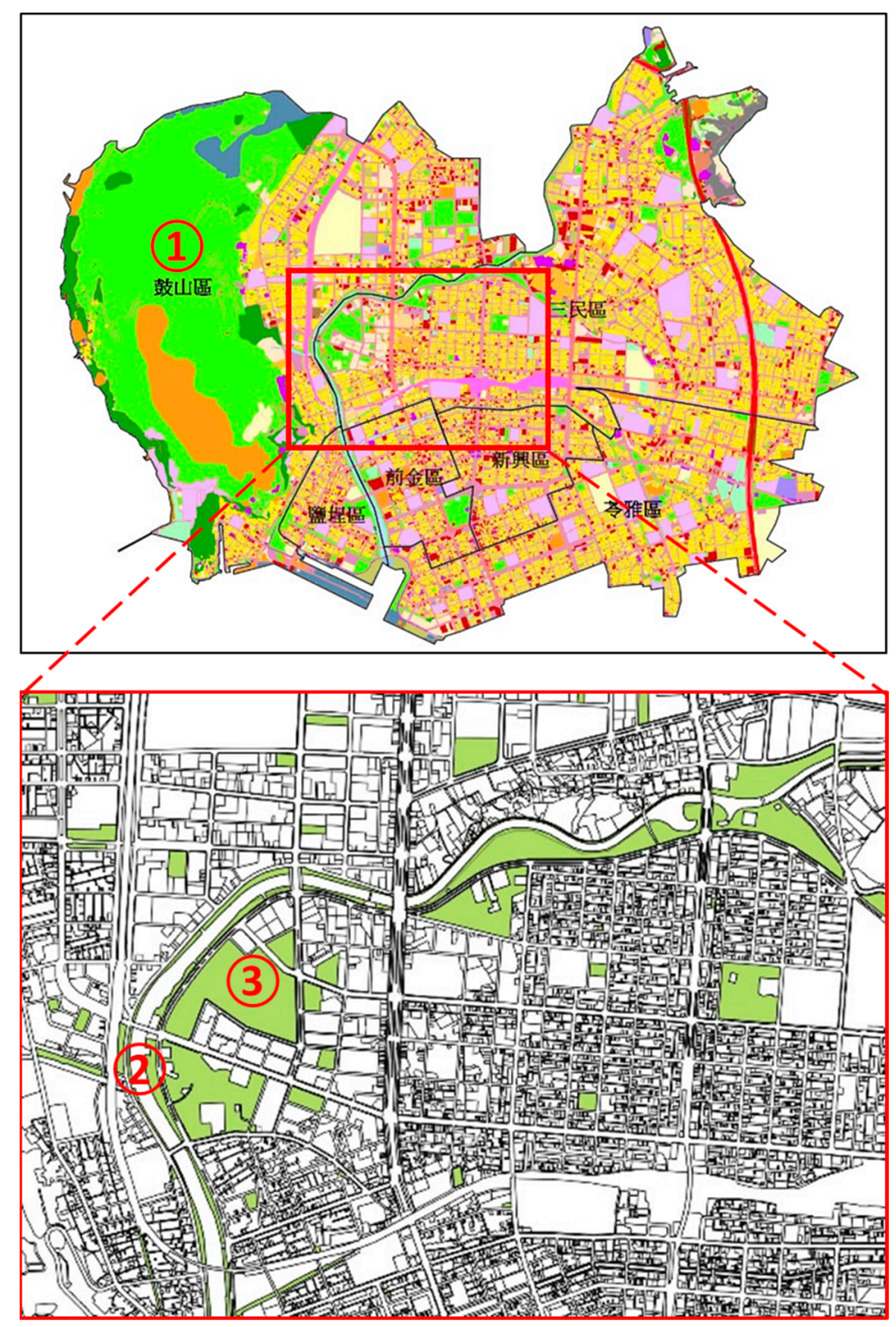

Figure 4. Using land use data to calculate the green space area (1. Shoushan National Nature Park, 2. Love River, 3. Zhongdu Wetlands Park). 


\section{Results and Recommendations}

3.1. Survey Results of Green Space Creation and PV Panel Installation under the Kaohsiung House Project

The construction projects that were approved under the Kaohsiung House Project between 2015 and 2018 were subjected to analysis, and the areas of green space and PV panel installation during this period were determined. The construction project data were used to identify the areas where green space would be created and power generation devices installed, respectively, in each construction stage. The measurement sites, which were located in the six major administrative districts of Kaohsiung, spanned the area of 117 construction projects. Figure 5 presents the spatial distribution of the construction projects that were completed over the course of the Kaohsiung House Project. Table 2 lists a compilation of the total area of green roofs, green balconies, and PV panels that were installed in each district. The panels in question were regular panels supplied by five Taiwanese manufacturers. The calculations indicated that, on average, a panel area of $8.01 \mathrm{~m}^{2}$ was necessary for generating $1 \mathrm{~kW}$ of power.

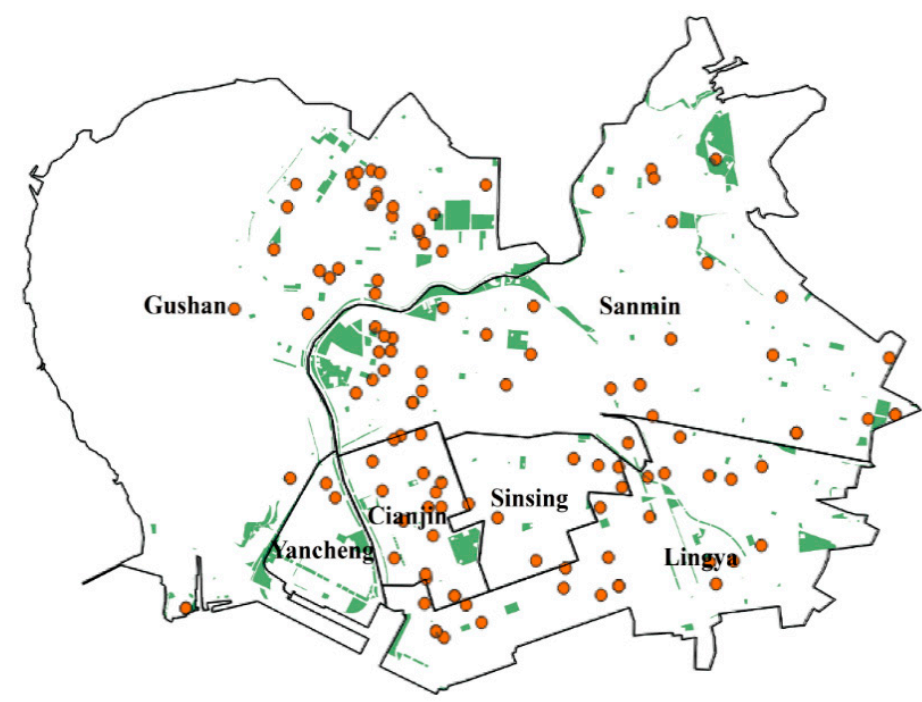

Figure 5. Spatial distribution of the construction projects in the six administrative districts approved under the Kaohsiung House Project.

Table 2. Area of PV panel installation and greening space in each administrative district.

\begin{tabular}{ccc}
\hline Administrative District & Estimated Area of PV Installation $\left.\mathbf{( m}^{\mathbf{2}}\right)$ & Area of Rooftop Greening $\mathbf{( m}^{\mathbf{2}} \mathbf{~}$ \\
\hline Sinsing District & 0.00 & 149.26 \\
Lingya District & 557.18 & 4459.98 \\
Cianjin District & 219.67 & 1055.68 \\
Sanmin District & 338.98 & 4299.27 \\
Yancheng District & 0.00 & 29.99 \\
Gushan District & 809.01 & 5389.13 \\
\hline Total & 1924.84 & $15,383.31$ \\
\hline
\end{tabular}

Figure 6 displays the proportion of the areas of rooftop greening and PV panel installation to the total area of each administrative district. Gushan District had the highest proportions of both ( $35 \%$ and $42 \%$, respectively). The proportion of the area of PV panel installation to the total area of Lingya District, 29\%, was fair. Because the number of construction projects in Sinsing District and Yancheng District was low, the proportions of areas of rooftop greening and panel installation were also low. In sum, the total area of PV panels increased by $1924.84 \mathrm{~m}^{2}$, which indicated that the area of PV panels in Kaohsiung will continue to increase under the Kaohsiung House Project. 


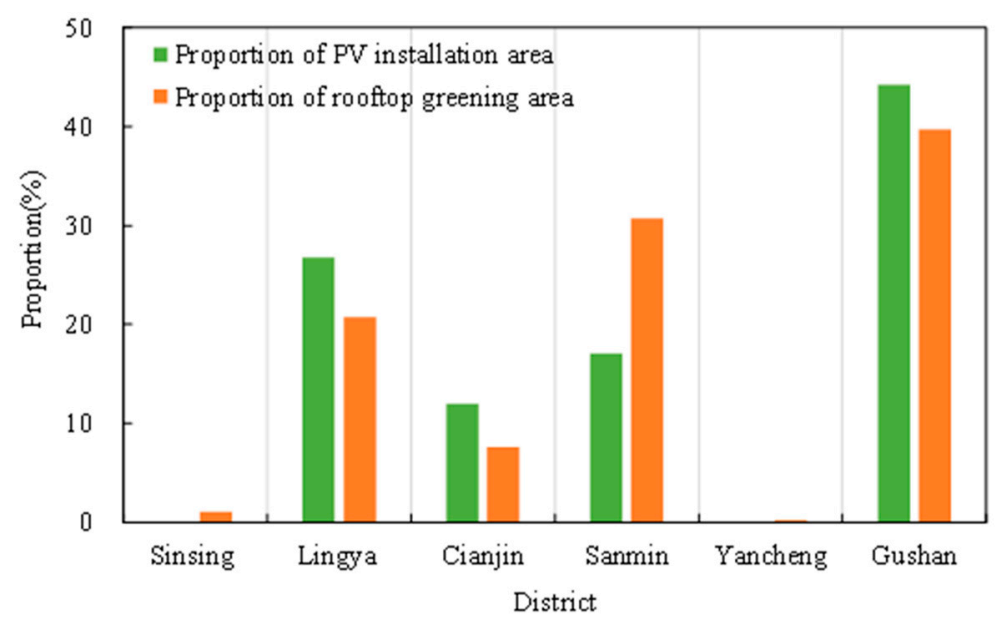

Figure 6. Proportions of areas with rooftop greening and PV panel installation to the total area of the six major administrative districts in Kaohsiung where the measurement sites were located.

\subsection{Analysis of Measurement Data}

Analysis was conducted on the temperature data that were collected between 25 March 2018 and 18 January 2019. This period spanned both summer and winter and was, therefore, sufficient for examining Kaohsiung's meteorological patterns. Because temperature is affected by factors, such as precipitation, wind speed, and cloud coverage, data on the daily precipitation amount, precipitation duration, and the hours and rate of insolation collected by a primary monitoring station in Kaohsiung (station code: 467440) was used as a reference. A sunny day was defined as having no precipitation and an insolation rate of at least $80 \%$ [36]. Under these criteria, 45 days during the hot season over the 289-day sampling period were considered to be sunny and subjected to further analysis. The hot season was defined as the period between April and August during which the highest temperatures were recorded. In order to determine the hourly temperature distribution trend, the hourly temperature data and the data on temperature differences among all of the measurement stations were compiled.

Figure 7 a presents the maximum temperature $\left(\mathrm{T}_{\mathrm{M}}\right)$, mean temperature (i.e., the average of all temperature readings collected at the specific hour), and minimum temperature $\left(\mathrm{T}_{\mathrm{m}}\right)$ at each hour of the day. In descending order of temperature, Ta95 and Ta5 indicated the temperatures at the 95th and 5th percentiles, respectively, at which outliers were identified. The analysis revealed that the mean city temperature began increasing at 6:00 a.m., exceeded $30^{\circ} \mathrm{C}$ between 8:00 a.m. and 5:00 p.m., with a highest temperature of $32.1^{\circ} \mathrm{C}$ being recorded at noon. Lower temperatures were observed between 6:00 p.m. and 5:00 a.m., with the lowest temperature of $26.7^{\circ} \mathrm{C}$ recorded at 5 a.m. The day-night temperature difference was $5.4^{\circ} \mathrm{C}$.

In general, urban heat island intensity is defined as the difference between the highest temperature that was measured in the urban area and the lowest temperature measured in the suburbs around the city [37]. Accordingly, the differences between the maximum and minimum temperatures in Figure 7a were calculated in order to determine the urban heat island intensity of Kaohsiung. $\mathrm{T}_{\mathrm{M}-\mathrm{m}}$ denotes the difference between the maximum and minimum temperatures at each hour, as depicted in Figure $7 \mathrm{~b}$. The difference between the temperatures at the 98th and 2nd percentiles and between those at the 95th and the 5th percentiles is denoted by $\Delta \mathrm{T}_{98-2}$, and $\Delta \mathrm{T}_{95-5}$, respectively.

Low urban heat island intensity was observed between 9:00 a.m. and 2:00 p.m. The minimum $\mathrm{TM}-\mathrm{m}$ value of $2.0^{\circ} \mathrm{C}$ was recorded at 1:00 p.m., which indicated that temperatures were comparably high across all the areas. Between evening and midnight, the temperature difference increased gradually, with the maximum difference of $3.4^{\circ} \mathrm{C}$ being recorded at 5:00 a.m. In other words, the stronger intensity indicated that the urban heat island effect was more notable at night. 


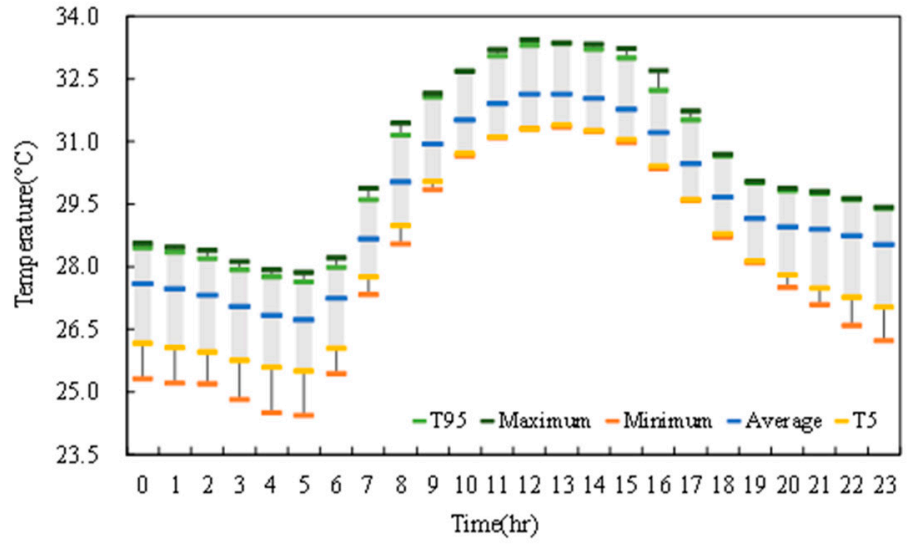

(a)

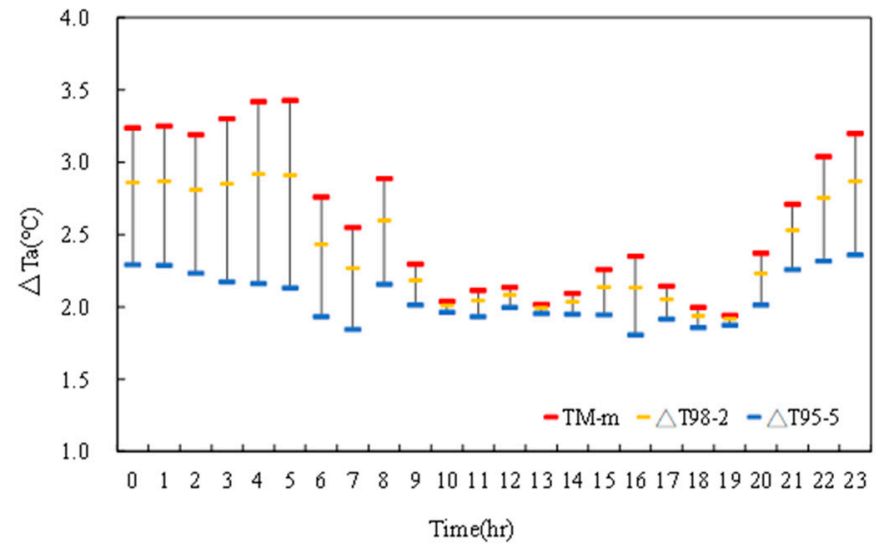

(b)

Figure 7. (a) Hourly temperature distribution in the hot season (April to August); (b) hourly temperature difference in the hot season (April to August).

\subsection{Temperature Distribution and PV Panel Power Generation Reduction}

The Geostatistical Wizard was used in order to optimize the parameter configurations and the types of data curves for Kriging interpolation (Table 1). Figure 8a presents the interpolation results of the mean temperature distribution during the hot season. The areas where the urban heat island effect was present are clearly observable. Sites E11, E12, and E13 constituted a boundary that separated the high- and low-temperature regions. Mean temperatures at sites F12, H13, and G13 (Kaohsiung Main Station, Jianguo Second Road, and Liuhe Road, respectively), which were located in the city center, collectively exceeded $30{ }^{\circ} \mathrm{C}$; hence, they were classified as high-temperature regions. Sites D11, E12, and E11 (Shoushan National Nature Park, Zhongdu Wetlands Park, and the Kaohsiung Museum of Fine Arts, respectively) were classified as low-temperature regions. The temperature difference between the high- and low-temperature regions was $2{ }^{\circ} \mathrm{C}$.

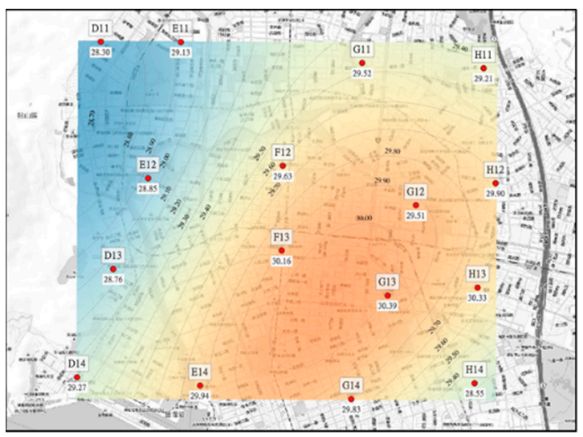

$28.5^{\circ} \mathrm{C}$

(a)

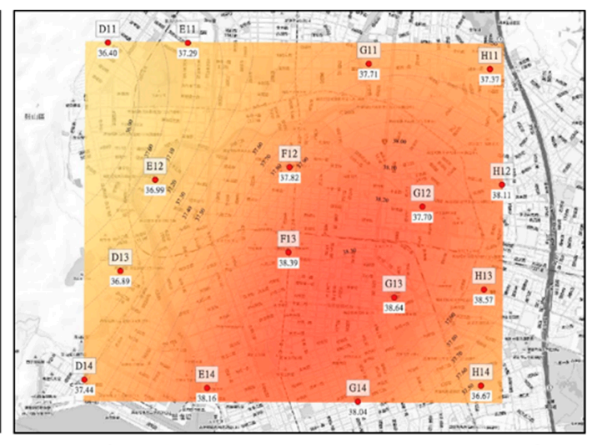

(b)

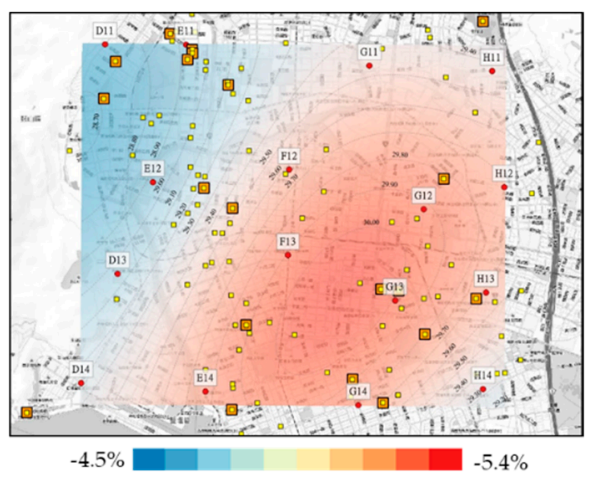

(c)

○ Measurement sites $\square$ Kaohsiung House constriction cases $\quad \square$ PV construction cases

Figure 8. Distributions of the (a) ambient temperature, (b) photovoltaic (PV) panel temperature, and (c) reduction coefficient during the hot season and distribution of PV panels installed under the Kaohsiung House Project.

The collected temperature data were used to estimate the generation efficiency of each panel in order to evaluate the effect of ambient temperature distribution on PV panels. In addition, the panel temperature and temperature reduction coefficients during the hot season were derived. The temperature data were substituted into Equation (4) to determine the panel temperature at each site. Next, interpolation was performed in order to map the distribution of panel temperature across the city. The panel temperature in the city center exceeded $38^{\circ} \mathrm{C}$, whereas that of low-temperature regions, such as site E11, remained under 
$37^{\circ} \mathrm{C}$, as illustrated in Figure $8 \mathrm{~b}$. Overall, the pattern was similar to that of the ambient temperature.

The temperature data were substituted into Equation (5) to determine the temperature reduction coefficient $C_{T}$ in order to assess the potential of solar power generation in the city and compare the generation efficiency in the high- and low-temperature regions, as presented in Figure 8c. In the urban area of Kaohsiung, without considering other meteorological factors and the efficiency of solar panels, the temperature reduction coefficient in the higher temperature areas of the city is estimated to be $-5.4 \%$, which means that solar panels that were installed in high-temperature areas will lose power generation efficiency by $5.4 \%$ due to temperature factors. In the low-temperature regions, the reduction coefficient was $-4.6 \%$, and the generation efficiency was accordingly higher. Relocating all of the PV panels installed in the high-temperature regions under the Kaohsiung House Project to low-temperature regions could increase the overall generation efficiency by $0.8 \%$.

The spatial distribution map of the construction projects completed under the Kaohsiung House Project was overlaid with the reduction coefficient distribution map to determine whether solar power generation was effectively promoted, according to Figure 8c. Of the 117 construction projects, 23 involved PV panel installation. Eight of these construction projects were near site G12, which was located in a high-temperature region, and six were near sites D11 and E11, which were located in low-temperature regions. The overall 5\% reduction in generation efficiency can be attributed to the fact that one-third of the panels installed were located in high-temperature regions.

\subsection{Greening Achievements in Kaohsiung}

The spatial distribution of plazas and green space in each administrative district (Table 3) was ascertained while using the GIS data on land use and statistics on green space from 2013 and 2018 provided by the Kaohsiung City government. Of the six administrative districts, Sinsing District had the lowest greening ratio of $1.8 \%$, followed by Gushan District at $2.0 \%$. However, Gushan District was still considered to be a low-temperature region; its low greening ratio can be ascribed to the fact that the mountainous region of the district (Shoushan National Nature Park) was excluded from the calculation. Yancheng District, which has the highest greening ratio at $10.4 \%$, has a green area of $161,381 \mathrm{~m}^{2}$ containing cultural parks, riverside green spaces, and green corridors. Although Sanmin District and Lingya District also had large areas of green space, they were fragmented over a large area that did not encompass the hotter locations in the city.

Table 3. Area of public green space in each administrative district. (data from Kaohsiung City government in 2018).

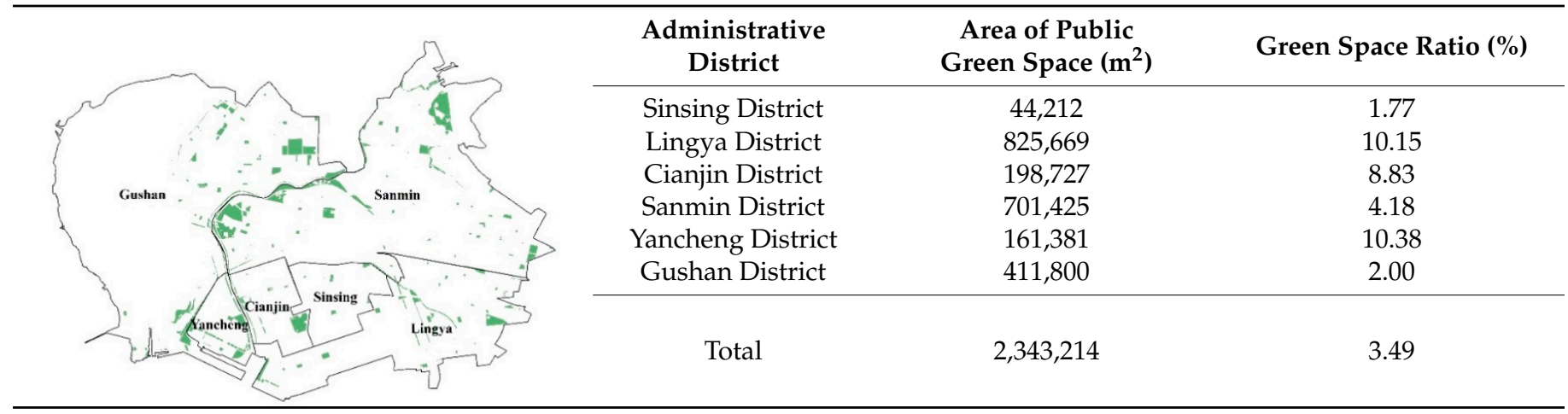

As mentioned, in order to explore the increase in green space under the Kaohsiung House Project, the greening areas planned in the construction projects approved under the Kaohsiung House Project were overlaid with the existing green space. The dark green space shown in Figure 9 denotes the expected increase in the green space ratio of each administrative district in the next three years. The results indicate that, under the ongoing realization of the Kaohsiung House Project, the increase in the green space ratio in the 
districts of Sinsing, Lingya, Cianjin, Sanmin, Gushan, and Yancheng will be of 0.06\%, $0.17 \%, 0.20 \%, 0.20 \%, 0.25 \%$, and $0.01 \%$, respectively. The small projected increase for Yancheng District can be explained by the fact that its existing green space spans a large area. Regarding the existing green space in Kaohsiung in general, Figure 8a shows that site F13 (Sinsing District) and sites F12 and G12 (Sanmin District) have higher temperatures, and the distribution graph indicates that the green spaces in these areas are fragmented, also small, or both. In other words, the projected growth in green space under the Kaohsiung House Project is insufficient for alleviating the urban heat island effect in these regions.

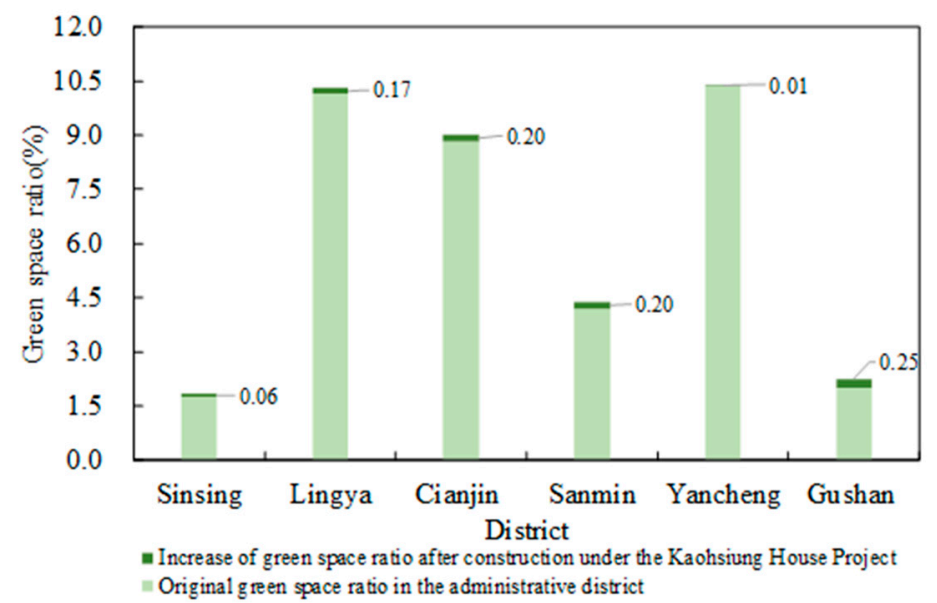

Figure 9. Increase of green space ratio in each administrative district after the implementation of the Kaohsiung House Project.

3.5. Recommendations for PV Panel Installation and Green Space Planning under the Kaohsiung House Project

Temperature affects the generation efficiency of PV panels in cities. High temperature reduces the generation efficiency, whereas low temperature increases it, according to the temperature reduction coefficient equation. In order to ensure that the PV panels that will be installed under the Kaohsiung House Project can achieve the maximum generation efficiency, despite the notable citywide difference in temperature, the hot season temperature distribution graph was segmented according to the administrative boundary of each district. The mean temperature of each district was determined and examined with the areas of the green space created and PV panels that were installed under the project. In Figure 10a,b, the yellow line denotes the mean temperature of each district. Figure 10a shows the mean temperature and area over which PV panels were installed in each district. Figure $10 \mathrm{~b}$ presents the mean temperature and area of green space constructed in each district. Sinsing District and Lingya District were the hottest regions, with mean temperatures exceeding $30.7^{\circ} \mathrm{C}$, as shown in Figure 10a. Gushan District had the lowest temperature recorded among all of the districts $\left(29.9^{\circ} \mathrm{C}\right)$ and was, thus, considered to be a low-temperature region. Districts Cianjin, Sanmin, and Yancheng had moderate temperatures that averaged to approximately $30.5^{\circ} \mathrm{C}$. 


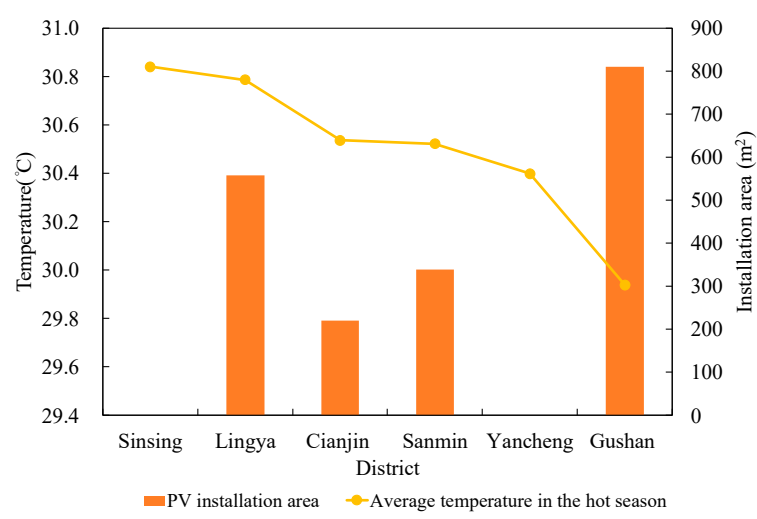

(a)

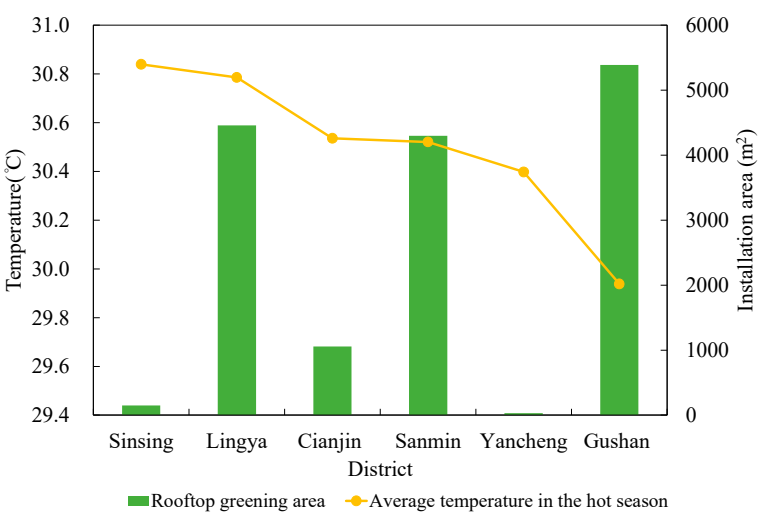

(b)

Figure 10. (a) Mean temperatures and area over which photovoltaic (PV) panels were installed in each district; (b) mean temperature and area of green space in each district.

Some recommendations for the future installation of PV panels and the construction of green space under the Kaohsiung House Project are presented as follows.

First, Figure 10a indicates higher temperatures in Sinsing District and Lingya District, which means that they are less suitable for PV panel installation. Currently, no plans for panel installation in Sinsing District, where the urban heat island effect can be better alleviated through greening facility construction, have been made. The panels that were planned for installation in Lingya District should be relocated to low-temperature regions, because its high temperatures would reduce their efficiency. The area of the green space in Sinsing District and Yaling District, which are both located in the city center, is insufficient for temperature reduction. Therefore, these districts should focus on increasing the area of rooftop and balcony greening to reduce the urban heat island effect.

Second, low-temperature regions, such as Gushan District, should increase the area of panel installation. Figure 10b indicates that the area of PV panels and greening facilities in Gushan District will be increased. In order to improve the overall generation efficiency of the panels across the city and prevent a district from becoming the next urban hot spot amid continual land development, panel installation should be prioritized and green space creation should be considered to be a compulsory complementary measure. Moderatetemperature districts are encouraged to emphasize both panel installation and green space construction. The temperature distribution graph that is presented in Figure 11 can also be used to plan the subsequent installation of panels and greening facilities under the Kaohsiung House Project. With temperatures of approximately $29.8^{\circ} \mathrm{C}$ to $30^{\circ} \mathrm{C}$, Region I should prioritize the construction of green space; with temperatures of approximately $29.3^{\circ} \mathrm{C}$ to $29.8^{\circ} \mathrm{C}$, Region II should focus on both panel installation and green space construction. With temperatures under $29.3^{\circ} \mathrm{C}$, Region III should prioritize panel installation. 


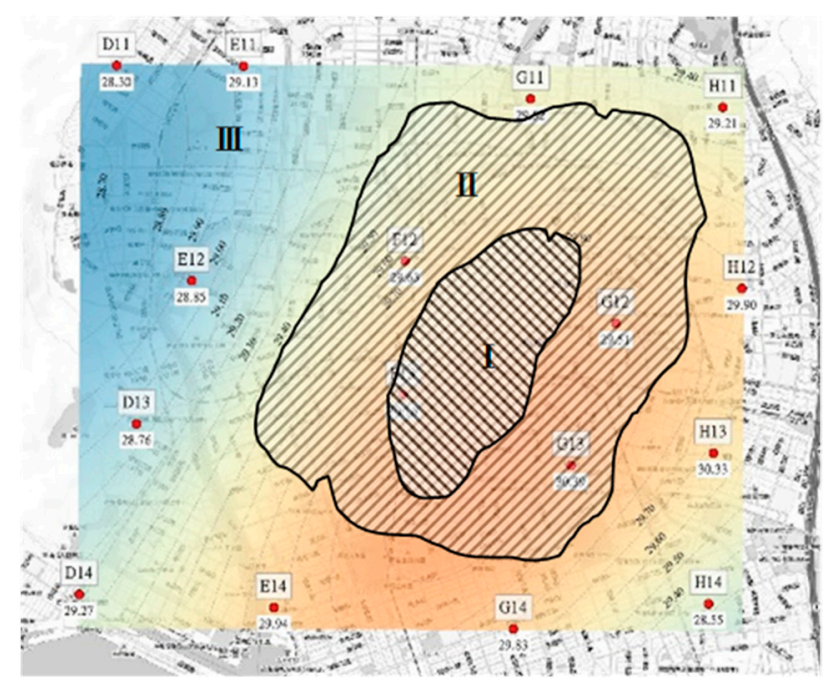

Figure 11. Regions for which photovoltaic panel installation and green space creation are recommended

\section{Conclusions}

Environmental sustainability constitutes a developmental focus for numerous countries. Urban greening can alleviate the urban heat island effect and, thereby, prevent excessive energy consumption. The use of green energy is an effective measure for reducing carbon emissions. The Kaohsiung House Project aims to mitigate urban heat islands in Kaohsiung and makes sources of green energy readily accessible. The 16 temperature measurement sites that were established across the city in March 2018 collected temperature data over 289 consecutive days. The collected data were screened and then subjected to Kriging interpolation to plot a map of temperature distributions in Kaohsiung during the hot season. Panel temperatures and temperature reduction coefficients were derived from the equation that was proposed by Pan et al. [27].

The main conclusions are as follows:

First, a difference of $2{ }^{\circ} \mathrm{C}$ between temperatures in the six administrative districts during the hot season (April-August) was observed. The area surrounding Kaohsiung Main Station has relatively high temperatures, whereas Zhongdu Wetland Park and the nearby Shoushan National Nature Park have relatively low temperatures. The analysis of the temperature monitoring network, the data of which can be used in order to assess the generation efficiency of PV panels that were installed across a large area of the city, revealed that the reduction coefficient in high-temperature regions reached $-5.4 \%$. Relocating the PV panels in these regions to Gushan District could enhance the overall generation efficiency by $0.8 \%$.

Second, the increase in green space area under the Kaohsiung House Project will result in a notable increase in the overall green space ratio across the six districts. The overlay of the green space constructed under the project and existing major areas of green space indicated that the continual implementation of the project would increase the green space ratio by $0.06 \%, 0.17 \%$, and $0.20 \%$ in districts Sinsing, Lingya, and Sanmin-regions with relatively high temperatures-respectively.

Third, regarding the planning direction for PV panel installation under the Kaohsiung House Project, this study analyzed the mean temperatures and areas for panel installation in each district. Gushan District had the lowest temperature. Therefore, the overall generation efficiency can be maximized by increasing the area of PV panels that were installed in this district. Sinsing District and Lingya District had relatively high temperatures and, thus, lower generation efficiency than that of Gushan District. Moreover, the area of the existing green space in these districts is insufficient. Therefore, project implementation should focus on rooftop and balcony greening in order to reduce the overall temperature and urban heat island effect. The areas surrounding site E12, Zhongdu Wetland Park, are effective 
in reducing the overall city temperature. PV panel installation and green space creation should both be prioritized to prevent exacerbation of the urban heat island effect caused by overdevelopment.

Finally, the present study used the temperature distribution data that were collected from each measurement site as a basis from which to make recommendations for the subsequent installation of green energy generation facilities in each administrative district. The findings can serve as a reference for the implementation of similar greening projects in other cities aimed to increase energy efficiency, reduce carbon emissions, and improve the outdoor thermal comfort.

Author Contributions: Collect project data C.-C.C.; installation of equipment and writing-review and editing, K.-A.H.; installation of equipment and data analysis, S.-Y.C.; formal analysis, F.-Y.L.; project guidance, T.-P.L. All authors have read and agreed to the published version of the manuscript.

Funding: The authors disclosed receipt of the following financial support for the research, authorship, and/or publication of this article: This work was supported by the Kaohsiung City government, under No. Gongwuu-Jian-Zi 10739037300 (Kaohsiung House Project).

Institutional Review Board Statement: Not applicable.

Informed Consent Statement: Not applicable.

Data Availability Statement: The data presented in this study are available in [The establishment and application of smart temperature and environment observation network in Kaohsiung (STONK)].

Acknowledgments: This study analyzed the air temperature map of Kaohsiung City on the basis of a project (No. Gongwuu-Jian-Zi 10739037300) funded by the Kaohsiung City government. We thank the Kaohsiung City government for providing data concerning the Kaohsiung House Project as well as relevant advice and assistance.

Conflicts of Interest: The authors declare no conflict of interest.

\section{References}

1. Li, X.; Zhou, Y.; Yu, S.; Jia, G.; Li, H.; Li, W. Urban heat island impacts on building energy consumption: A review of approaches and findings. Energy 2019, 174, 407-419. [CrossRef]

2. Lin, H.T.; Kuo, H.C.; Lee, K.P.; Chen, T.C.; Chen, K.T. Experimental Analyses on Urban Heat Island Effect and Its Improvement Strategies in Coastal Cities of Taiwan-Analyses for Tainan, Kaohsiung and Hsinchu. City Plan. 2001, $28,323-341$.

3. Chen, R.; You, X. Reduction of urban heat island and associated greenhouse gas emissions. Mitig. Adapt. Strateg. Glob. Chang. 2020, 25, 689-711. [CrossRef]

4. Maiolo, M.; Pirouz, B.; Bruno, R.; Palermo, S.A.; Arcuri, N.; Piro, P. The Role of the Extensive Green Roofs on Decreasing Building Energy Consumption in the Mediterranean Climate. Sustainability 2020, 12, 359. [CrossRef]

5. He, Y.; Yu, H.; Ozaki, A.; Dong, N. Thermal and energy performance of green roof and cool roof: A comparison study in Shanghai area. J. Clean. Prod. 2020, 267, 122205. [CrossRef]

6. Lehnert, M.; Tokar, V.; Jurek, M.; Geletič, J. Summer thermal comfort in Czech cities: Measured effects of blue and green features in city centres. Int. J. Biometeorol. 2020. [CrossRef]

7. Susca, T. Green roofs to reduce building energy use? A review on key structural factors of green roofs and their effects on urban climate. Build. Environ. 2019, 162, 106273. [CrossRef]

8. Morakinyo, T.E.; Dahanayake, K.W.D.K.C.; Ng, E.; Chow, C.L. Temperature and cooling demand reduction by green-roof types in different climates and urban densities: A co-simulation parametric study. Energy Build. 2017, 145, 226-237. [CrossRef]

9. Besir, A.B.; Cuce, E. Green roofs and facades-A comprehensive review. Renew. Sustain. Energy Rev. 2018, 82, 915-939. [CrossRef]

10. Smith, K.R.; Roebber, P.J. Green roof mitigation potential for a proxy future climate scenario in Chicago, Illinois. J. Appl. Meteorol. Climatol. 2011, 50, 507-522. [CrossRef]

11. Aflaki, A.; Mirnezhad, M.; Ghaffarianhoseini, A.; Ghaffarianhoseini, A.; Omrany, H.; Wang, Z.H.; Akbari, H. Urban heat island mitigation strategies: A state-of-the-art review on Kuala Lumpur, Singapore and Hong Kong. Cities 2017, 62, 131-145. [CrossRef]

12. Sustainable Smart Town Provides Better Lifestyles as the Entire Town. Available online: https://www.panasonic.com/global/ corporate/sustainability/case_study/case01.html (accessed on 17 February 2020).

13. Chatzidimitriou, A.; Yannas, S. Microclimate design for open spaces: Ranking urban design effects on pedestrian thermal comfort in summer. Sustain. Cities Soc. 2016, 26, 27-47. [CrossRef]

14. Mutani, G.; Vicentini, G. Buildings' energy consumption, energy savings potential and the availability of renewable energy sources in urban spaces. J. Civ. Eng. Archit. Res. 2015, 2, 1102-1115. 
15. Zheng, Y.; Weng, Q. Modeling the Effect of Green Roof Systems and Photovoltaic Panels for Building Energy Savings to Mitigate Climate Change. Remote Sens. 2020, 12, 2402. [CrossRef]

16. Rupasinghe, H.T.; Halwatura, R.U. Benefits of implementing vertical greening in tropical climates. Urban For. Urban Green 2020, 53, 126708. [CrossRef]

17. Battisti, A.; Laureti, F.; Zinzi, M.; Volpicelli, G. Climate Mitigation and Adaptation Strategies for Roofs and Pavements: A Case Study at Sapienza University Campus. Sustainability 2018, 10, 3788. [CrossRef]

18. Chen, Y.; Zheng, B.; Hu, Y. Numerical Simulation of Local Climate Zone Cooling Achieved through Modification of Trees, Albedo and Green Roofs-A Case Study of Changsha, China. Sustainability 2020, 12, 2752. [CrossRef]

19. Santiago, I.; Trillo-Montero, D.; Moreno-Garcia, I.M.; Pallarés-López, V.; Luna-Rodríguez, J.J. Modeling of photovoltaic cell temperature losses: A review and a practice case in South Spain. Renew. Sustain. Energy Rev. 2018, 90, 70-89. [CrossRef]

20. Foshag, K.; Aeschbach, N.; Höfle, B.; Winkler, R.; Siegmund, A.; Aeschbach, W. Viability of public spaces in cities under increasing heat: A transdisciplinary approach. Sustain. Cities Soc. 2020, 59, 102215. [CrossRef]

21. Lin, T.P.; Lin, F.Y.; Wu, P.R.; Hämmerle, M.; Höfle, B.; Bechtold, S.; Hwang, R.L.; Chen, Y.C. Multiscale analysis and reduction measures of urban carbon dioxide budget based on building energy consumption. Energy Build. 2017, 153, 356-367. [CrossRef]

22. Correa-Betanzo, C.; Calleja, H.; DeLeón-Aldaco, S. Module temperature models assessment of photovoltaic seasonal energy yield. Sustain. Energy Technol. Assess. 2018, 27, 9-16. [CrossRef]

23. Mekhilef, S.; Saidur, R.; Kamalisarvestani, M. Effect of dust, humidity and air velocity on efficiency of photovoltaic cells. Renew. Sustain. Energy Rev. 2012, 16, 2920-2925. [CrossRef]

24. Dubey, S.; Sarvaiya, J.N.; Seshadri, B. Temperature dependent photovoltaic (PV) efficiency and its effect on PV production in the world-A review. Energy Procedia 2013, 33, 311-321. [CrossRef]

25. Nogueira, C.E.C.; Bedin, J.; Niedzialkoski, R.K.; DeSouza, S.N.M.; DasNeves, J.C.M. Performance of monocrystalline and polycrystalline solar panels in a water pumping system in Brazil. Renew. Sustain. Energy Rev. 2015, 51, 1610-1616. [CrossRef]

26. Pinho, J.T.; Galdino, M.A. Manual de Engenharia Para Sistemas Fotovoltaicos, 1st ed.; CEPEL-CRESESB: Rio de Janeiro, Brazil, 2014; pp. 47-499.

27. Pan, J.; Shen, Y.; Bian, Z.; Wang, X. Effects of Meteorological Elements on Solar Cell Temperature. J. Appl. Meteorol. Sci. 2014, 25, 150-157.

28. Honjo, T.; Yamato, H.; Mikami, T.; Grimmond, C.S.B. Network optimization for enhanced resilience of urban heat island measurements. Sustain. Cities Soc. 2015, 19, 319-330. [CrossRef]

29. Chen, Y.C.; Yao, C.K.; Honjo, T.; Lin, T.P. The application of a high-density street-level air temperature observation network (HiSAN): Dynamic variation characteristics of urban heat island in Tainan, Taiwan. Sci. Total Environ. 2018, 626, 555-566. [CrossRef]

30. Eldrandaly, K.A.; Abu-Zaid, M.S. Comparison of six GIS-based spatial interpolation methods for estimating air temperature in western Saudi Arabia. J. Environ. Inform. 2011, 18, 38-45. [CrossRef]

31. Seyedmohammadi, J.; Esmaeelnejad, L.; Shabanpour, M. Spatial variation modelling of groundwater electrical conductivity using geostatistics and GIS. Model Earth Syst. Environ. 2016, 2, 1-10. [CrossRef]

32. Feng, F.L.; Huang, C.C. The study of parameters of stand structure by using the spatial interpolation model. Bull. Exp. For. Natl. Chung Hsing Univ. 1997, 19, 1-18.

33. Li, J.; Heap, A.D. A Review of Spatial Interpolation Methods for Environmental Scientists; Geoscience Australia: Canberra, Australia, 2008.

34. García, M.C.A.; Balenzategui, J.L. Estimation of photovoltaic module yearly temperature and performance based on Nominal Operation Cell Temperature calculations. Renew. Energy 2004, 29, 1997-2010. [CrossRef]

35. Hu, H.; Yuan, D.; Wang, T.; Jiang, Y. Dynamic performance of high concentration photovoltaic or thermal system with air temperature and humidity regulation system (HCPVTH). Appl. Therm. Eng. 2019, 146, 577-587. [CrossRef]

36. Liao, Y.J. The Application of a High-Density Street-Level Air Temperature Observation Network (HiSAN): The Relationship between Air Temperature and Land Use and Land Cover. Master's Thesis, National Cheng Kung University, Tainan City, Taiwan, 2018.

37. Lin, H.T.; Sun, C.Y.; Kuo, H.C.; Lee, K.P. A Study of Urban Populations and the Urban Heat Island Intensity in Tainan. J. City Plan. 2005, 32, 83-97. 